\title{
Geographic variability in the incidence and heritability of wing dimorphism in the striped ground cricket, Allonemobius fasciatus
}

Timothy A. Mousseau* and

Derek A. Roff
Department of Biology, McGill University, Montréal, Québec, Canada H3A 1 B1.

We examined nine Allonemobius fasciatus populations for variation in the incidence and heritability of wing dimorphism. When reared in the laboratory, the incidence of long winged forms varied significantly among populations (from 9 to 74 per cent), and sexes, with females usually producing a larger proportion of long winged individuals than males. The heritability of wing length, averaged across populations, was $0.52 \pm 0.14$ for males and $0.72 \pm 0 \cdot 15$ for females, and did not vary significantly among populations. There was no apparent relationship between either the incidence or the heritability of wing length and the geographic origin of the founding population.

\section{INTRODUCTION}

Wings usually bestow the power of flight and the ability to disperse in search of food or mates, or to migrate when environmental conditions deteriorate (Roff, 1984, 1986a,b). Yet in many pterygote insects wing dimorphism is common (Roff, 1986b). Recent evidence suggests that possession of long functional wings often entails a cost to fitness, usually in the form of reduced fecundity and/or a delay in the time at first reproduction in the long winged morph (Dingle, 1980; Harrison, 1980; Roff, 1986a). Roff (1986b) has proposed that "the frequency of the two wing morphs (long and short) in a population will depend upon the stability of the habitat, the benefits such as increased fecundity of being flightless, and the genetic basis of the trait".

Relatively little is known of the genetics of wing dimorphism. Of the 23 insect species examined by Roff (1986a), eight appeared to inherit wing length in a Mendelian fashion, while fourteen exhibited polygenic genetic determination of pterogomorphism. Within the sand cricket, Gryllus firmus, the family means of wing length incidence were found to vary continuously within a population, and to possess high heritabilities, on the order of 0.55 to 0.68 (Roff, 1986b) clearly indicating the potential for selection to act within populations. However,

* Present address: Department of Entomology, University of California, Davis, USA 95616. interpopulation variability in the genetics of wing polymorphism has not until now been addressed.

The purpose of this study was to examine geographic and sex linked patterns in the heritability of wing dimorphism in the striped ground cricket, Allonemobius fasciatus. This species is widely distributed in North America (Alexander and Thomas, 1959) and has been found to exhibit genetically based geographical variation in body size, ovipositor length, diapause propensity, development times, and the thermal requirements for development (Mousseau, 1988). In addition there is evidence to suggest a significant cost to the possession of functional wings in this species: short winged females (which cannot fly) produce on average more eggs and intiate egg production at an earlier date following the final molt than do long winged females (Roff, 1984). Long winged males may also suffer delays in maturity and reduced sperm production (Roff, unpublished data). However, variation among wing morph in nymphal growth and development rates may tend to compensate for these apparent costs (Mousseau, 1988).

Here, we present the heritability of wing dimorphism in nine widely distributed populations. We test for geographically related heterogeneity in the incidence and heritability of wing expression, and determine the coincidence between sexes in any discernible patterns of geographic variation. 


\section{METHODS}

Allonemobius fasciatus was collected from nine locations chosen to span much of this species latitudinal and altitudinal range along the east coast of North America (table 1). A minimum of one hundred individuals was collected from each population, and upon return to the laboratory crickets were placed in plastic mouse cages $(30 \times$ $17 \times 14 \mathrm{~cm})$ and provided with iceberg lettuce, crushed Purina cat chow, a cotton corked water vial, strips of kraft paper for cover, and a plastic sandwich box $(12 \times 12 \times 3.5 \mathrm{~cm})$ filled with sterilized potting soil for ovipositing. Glass lids and elastic bands were used to seal the cages. Maintenance was provided twice weekly. These stock populations were permitted to breed randomly, and to complete a minimum of two generations prior to the initiation of experiments.

Between 45 and 74 mating pairs were established for each experimental population. Virginity of females was assured by collecting within one day of final ecdysis. Each mated pair was placed in a plastic sandwich box $(12 \times 12 \times 3.5 \mathrm{~cm})$ containing approximately $1 \mathrm{gm}$ of crushed Purina cat chow and some iceberg lettuce. Females laid their eggs in a $25 \times 30 \mathrm{~cm}$ piece of cheese cloth that had been loosely rolled, moistened and placed into the deep half of a $37 \mathrm{~mm}$ petri dish. Boxes were cleaned twice weekly and eggs removed every five to seven days. Eggs were extracted from the cheese cloth, put onto moistened paper towels, placed into $7 \mathrm{~cm}$ petri dishes (egg dishes) and incubated at $30^{\circ} \mathrm{C}$ and 14:10 hrs LD for fifteen days. Egg dishes were checked daily; hatched nymphs were counted and placed into plastic boxes which had been equipped as those of the parents (minus the egg dish). All nymphs were reared at a maximum density of sixty per cage and maintenance was provided twice weekly. Following development, individuals were removed from cages and scored as to sex and wing length (long or short).

The heritability of wing length was estimated using a two-tiered approach. First, the intraclass correlation $(t)$ of family incidence of long winged offspring ( $0: 1$ data) was estimated using three methods which we refer to as the ANOVA method (Elston, 1977), the Maximum Likelihood method, and the $\chi^{2}$ method (Robertson, 1951). Using the ANOVA method, the intraclass correlation is calculated as:

$$
t=\left(\mathrm{MS}_{\mathrm{a}}-\mathrm{MS}_{\mathrm{w}}\right) /\left(\mathrm{MS}_{\mathrm{a}}+(k-1) \mathrm{MS}_{\mathrm{w}}\right)
$$

where

$$
\begin{aligned}
\mathrm{MS}_{\mathrm{a}} & =\left(\sum m_{i}^{2} / n_{i}-\left(\sum m_{i}\right)^{2} / N\right) /(C-1), \\
\mathrm{MS}_{\mathrm{w}} & =\left(\sum m_{i}-\sum m_{i}^{2} / n_{i}\right) /(N-C), \\
k & =\left(N-\sum n_{i}^{2} / N\right) /(C-1),
\end{aligned}
$$

and $m_{i}$ is the number of long winged individuals in family $i, n_{i}$ is the total number of offspring in family $i, C$ is the number of families, and $N$ is the total number of individuals in the study population.

Using the $\chi^{2}$ method $t$ is calculated as:

$$
t=\left(\chi^{2}-(C-1)\right) / G
$$

where

$$
\begin{aligned}
\chi^{2} & =\left(\sum m_{i}^{2} / n_{i}-\left(\sum m_{i}\right)^{2} / N\right) /(p(1-p)) \\
G & =\sum n_{i}-\left(\sum n_{i}^{2} / \sum n_{i}\right)-(C-1)
\end{aligned}
$$

and $p$ is the mean proportion of long winged individuals per family (Bull et al., 1982):

$$
p=(1 / C) \sum\left(m_{i} / n_{i}\right) \text {. }
$$

The maximum likelihood estimate of $t$ is estimated as:

$$
t=\left(2 p(1-p) \sum K_{i}\right) / \sum n_{i}\left(n_{i}-1\right)
$$

Table 1 A description of the study populations. Season lengths were calculated as mean annual degree days $>13^{\circ} \mathrm{C}$, except for populations denoted by $*$ which were estimated from latitude and elevation. Transition zone populations contained mixtures of both univoltine and bivoltine crickets

\begin{tabular}{lcccc}
\hline Population & Latitude & $\begin{array}{l}\text { Elevation } \\
(\mathrm{m})\end{array}$ & $\begin{array}{l}\text { Season length } \\
\left({ }^{\circ} . \mathrm{d}>13 \mathrm{C}\right)\end{array}$ & Life history \\
\hline Montréal, Québec & $45^{\circ} 30^{\prime} \mathrm{N}$ & 30 & 851 & Univoltine \\
Licklog Ridge, North Carolina & $35^{\circ} 32^{\prime} \mathrm{N}$ & 1500 & $1200^{*}$ & Univoltine \\
Asheville AP, North Carolina & $35^{\circ} 37^{\prime} \mathrm{N}$ & 700 & 1435 & Univoltine \\
Horsegap, North Carolina & $35^{\circ} 50^{\prime} \mathrm{N}$ & 600 & $1500^{*}$ & Univoltine \\
Richmond, Virginia & $37^{\circ} 32^{\prime} \mathrm{N}$ & 30 & 1857 & Univoltine \\
J. H. Kerr Dam, Virginia & $36^{\circ} 35^{\prime} \mathrm{N}$ & 70 & 1833 & Transition \\
Oxford, North Carolina & $36^{\circ} 20^{\prime} \mathrm{N}$ & 100 & 1968 & Transition \\
Toccoa, Georgia & $34^{\circ} 34^{\prime} \mathrm{N}$ & 300 & 2007 & Bivoltine \\
Winder, Georgia & $33^{\circ} 59^{\prime} \mathrm{N}$ & 290 & 2011 & Bivoltine \\
\hline
\end{tabular}


where

$$
\begin{aligned}
K_{i} & =0 \cdot 5(a+b+c), \\
a & =\left(m_{i}\left(m_{i}-1\right)\right) / p^{2}, \\
b & =\left(\left(n_{i}-m_{i}\right)\left(n_{i}-m_{i}-1\right)\right) /(1-p)^{2},
\end{aligned}
$$

and

$$
c=\left(2 m_{i}\left(n_{i}-m_{i}\right)\right) / p(1-p) .
$$

The heritability is then estimated from the intraclass correlations using the methodology outlined by Bull et al. (1982) and by Robertson and Lerner (1949) where:

$$
h^{2}=2 t p(1-p) / z^{2}
$$

and $z$ is the ordinate on the standardised normal curve which corresponds to a probability $p$. The standard error of the estimate was calculated as:

$$
\begin{aligned}
\text { S.E. }\left(h^{2}\right)= & 2 p(1-p)(1-t)(1+(k-1) t) / z^{2} \\
& \times \sqrt{\left(2(N-1) / k^{2}(C-1)(N-C)\right)} .
\end{aligned}
$$

\section{RESULTS AND DISCUSSION}

In fig. 1 it is shown that the distribution of family incidence of long winged offspring (i.e., the proportion of long winged offspring within a full-sib family) is continuous regardless of parental phenotype. However, short winged parents did produce on average fewer long winged offspring than did crosses between long winged parents, while "mixed" parents produced a distribution of family incidence intermediate between those of the monotypic parental crosses. These observations suggest a polygenic basis to wing dimorphism in the striped ground cricket.

In all populations there were more long winged females than males, though comparing across populations there was a good correlation $(r=0.93$, $t=6.7, P<0.001$ ) between the proportions of male and female macropters within a population (i.e., a population that produced a high percentage of long winged males also produced many long winged females). Neither the mechanism nor the adaptive significance to such intersexual variation is at present known.

The heritability of wing length (table 2) averaged $0.52 \pm 0.14$ for males and $0.72 \pm 0.15$ for females, and did not vary significantly among populations (one way ANOVA using means and S.E.'s (Zar, 1984), males: $F=1 \cdot 34$, df $=8222, P>$ $0 \cdot 2$; females: $F=1 \cdot 38, \mathrm{df}=8221, P>0 \cdot 2$ ). The differences between sexes were, however, sig-

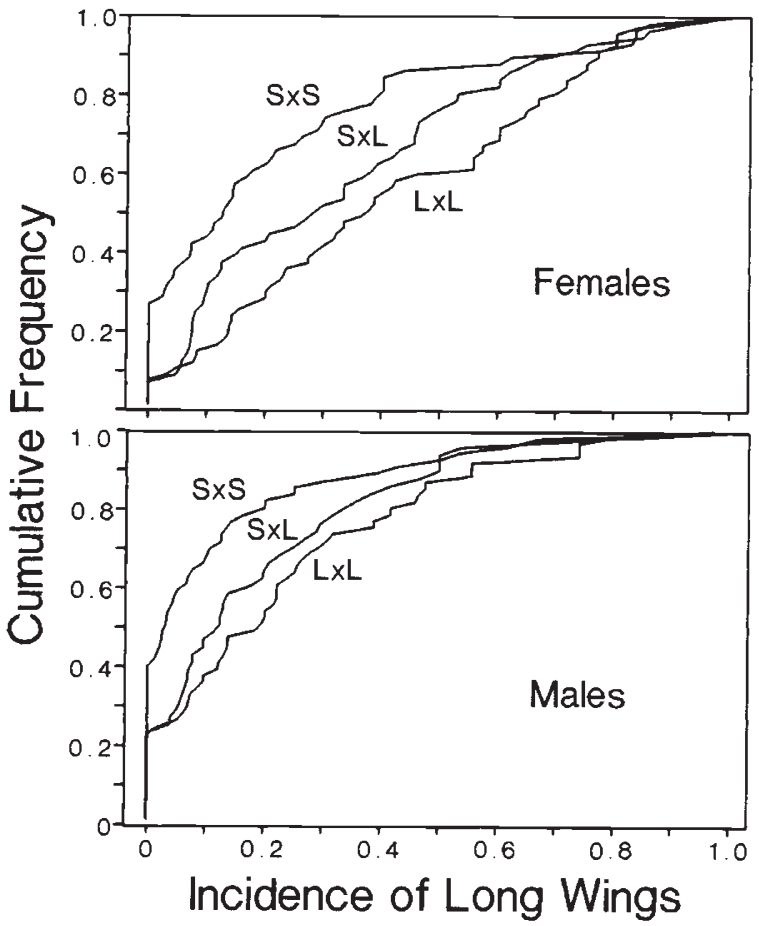

Figure 1 The cumulative frequency distributions of the incidence of long winged offspring in 242 full-sib families. $\mathrm{S} \times \mathrm{S}$ indicates crosses between short winged parents, $\mathrm{L} \times \mathrm{L}$ denotes crosses between long winged parents, while $\mathrm{S} \times \mathrm{L}$ indicates families of mixed parentage (i.e., long $\times$ short and short $\times$ long). The distributions are plotted separately for male and female offspring because of the sex related differences in the incidence of long wingedness.

nificant (paired $t$-test: $D=0 \cdot 18 \pm 0 \cdot 07, \mathrm{df}=8, t=$ $2.57, P<0.04)$, though there were indications that the estimated heritability for males and females within a population was associated $(r=0.62, t=$ $2 \cdot 1, \mathrm{df}=8, P<0 \cdot 04)$. There was no significant relationship between the incidence of long wings and heritability in males $(r=-0 \cdot 27, t=0 \cdot 74, P>$ $0 \cdot 4)$ but macroptery and its heritability were strongly correlated in females $(r=-0 \cdot 82, t=-3 \cdot 8$, $\mathrm{df}=8, P<0.007)$. However, these negative correlations between incidence and heritability might possibly be a consequence, in whole or in part, of the method employed to transform the intraclass correlation, $t$, from the binomial to the normal scale (Olausson and Rönningen, 1975).

Our estimates of the heritability of wing dimorphism in the striped ground cricket are similar to those reported for the sand cricket, Gryllus firmus $\left(h^{2}=0.62 \pm 0.08\right.$ and $0.68 \pm 0.09$ for males and females, respectively; Roff, 1986b). Roff (1986b) also found a higher incidence of long 
Table 2 The heritability of macroptery. Populations are ranked according to mean annual season length and heritability estimates are presented $t 1 \mathrm{~S}$.E. The sexes were computed separately because of significant differences in the incidence of macroptery. Combined heritability estimates represent the average across populations, weighted by the reciprocal of the sampling variance

\begin{tabular}{|c|c|c|c|c|c|c|}
\hline & \multirow[b]{2}{*}{ Families } & \multirow[b]{2}{*}{$N$} & \multicolumn{2}{|c|}{ Macroptery (\%) } & \multicolumn{2}{|l|}{ Heritability } \\
\hline & & & Males & Females & Males & Females \\
\hline Montréal & 12 & 271 & 18 & 18 & $1.65 \pm 0.53$ & $1.65 \pm 0.53$ \\
\hline Licklog & 13 & 520 & 11 & 28 & $0.56 \pm 0.33$ & $0 \cdot 82 \pm 0 \cdot 31$ \\
\hline Asheville & 32 & 293 & 59 & 74 & $0 \cdot 16 \pm 0.26$ & $0 \cdot 31 \pm 0 \cdot 23$ \\
\hline Horsegap & 31 & 899 & 32 & 42 & $0.71 \pm 0.20$ & $0.78 \pm 0.18$ \\
\hline Richmond & 32 & 1375 & 26 & 35 & $0 \cdot 42 \pm 0 \cdot 14$ & $0.63 \pm 0.16$ \\
\hline J. H. Kerr & 31 & 864 & 16 & 38 & $0.59 \pm 0.20$ & $0.73 \pm 0.19$ \\
\hline Oxford & 32 & 1573 & 6 & 9 & $0.30 \pm 0.16$ & $1 \cdot 63 \pm 0 \cdot 35$ \\
\hline Toccoa & 34 & 1191 & 21 & 32 & $0 \cdot 57 \pm 0 \cdot 16$ & $0 \cdot 56 \pm 0 \cdot 16$ \\
\hline Winder & 27 & 1074 & 29 & 40 & $0.79 \pm 0.20$ & $0 \cdot 88 \pm 0 \cdot 21$ \\
\hline Combined & 244 & 8060 & 24 & 35 & $0 \cdot 52 \pm 0 \cdot 14$ & $0 \cdot 72 \pm 0 \cdot 15$ \\
\hline
\end{tabular}

winged individuals and greater heritabilities among females than among males. This finding is generally true among Orthoptera, but is not so for other insect orders (Roff, 1986b).

We found significant heterogeneity among populations in the incidence of wing dimorphism (table 2; one way ANOVA of family incidence, transformed to normal, sexes treated separately, males: $F=7 \cdot 7, \mathrm{df}=8222, P<0 \cdot 0001$; females: $F=10 \cdot 9, \mathrm{df}=8221, P<0 \cdot 0001)$ with the Asheville population producing approximately 66 per cent long winged individuals while the Oxford population produced on average only $7-8$ per cent long winged individuals. However, there were no strong associations between the incidence of long wings within a population and the latitude $(r=-0.39)$, altitude $(r=0.07)$, or season length $(r=0)$ of geographic origin. Our failure to detect a relationship between the incidence of long wings within a population and coarse environmental variables could suggest non-adaptive variation as a result of random drift. Alternatively, variation in the expression of wing dimorphisn in this species probably reflects biological factors not directly related to season length (i.e. factors we have not measured).

To our knowledge, this is the first examination of geographic variability of the genetics of wing polymorphism in insects. We conclude that in most A. fasciatus populations, sufficient heritabilities exist for selection to proceed uninhibited, although further study is required in order to ascertain the repercussions to fitness of the phenotypic correlations often found between the possession of functional wings, and patterns of development and reproduction (Mousseau, 1988; Harrison, 1980; Roff, 1986a).
Acknowledgements We thank K. Heshka, S. David and L. Ogilvy for their invaluable help in rearing and measuring crickets. This study was supported by a McConnell Doctoral Fellowship to T.A.M., and by NSERC operating grant A7764 to D.A.R.

\section{REFERENCES}

ALEXANDER, R. D. AN1) THOMAS, E. S. 1959. Systematic and behavioral studies on the crickets of the Nemobius fasciatus group (Orthoptera: Gryllidae: Nemobiinae). Ann. Ent. Soc., Am., 52, 591-605.

BULL, J. J., VOGT, R. C. AND BULMER, M. G. 1982. Heritability of sex ratio in turtles with environmental sex determination. Evolution, 36, 333-341.

DINGLE, H. 1980. Ecology of evolution and migration. In Gauthreaux, S. A., Jr. (ed.) Animal migration, Orientation, and Navigation, Academic Press, New York.

ELSTON, R. V. 1977. Estimating "Heritability" of a dichotomous trait. Response. Biometrics, 33, 232-233.

HARRISON, R. G. 1980. Dispersal polymorphism in insects. Ann. Rev. Ecol. Syst., 11, 95-118.

MOUSseau, T. A. 1988. Life History Evolution in a Seasonal Environment: A Case Study. Ph.D. Thesis, McGill University.

OLAUSSON, A. AND RÖNNINGEN, K. 1975. Estimation of genetic parameters for threshold characters. Acta Agric. Scand., 25, 201-208.

ROBERTSON, A. 1951. The analysis of heterogeneity in the binomial distribution. Ann. Eugenics, 16, 1-15.

ROBERTSON, A. AND LERNER, I. M. 1949. The heritability of all-or-none traits: viability in poultry. Genetics, 34, 395-411.

ROFF, D. A. 1984. The cost of being able to fly: a study of wing polymorphism in two species of crickets. Oecologia, 63, 30-37.

ROFF, D. A. 1986a. The evolution of wing dimorphism in insects. Evolution, 40, 1009-1020.

ROFF, D. A. 1986b. The genetic basis of wing dimorphism in the sand cricket, Gryllus firmus and its relevance to the evolution of wing dimorphisms in insects. Heredity, 57, $221-231$

ZAR, J. H. 1984. Biostatistical Analysis, 2nd edn. Prentice-Hall, New Jersey. 